\title{
Different Lip Asymmetry in Adults Who Stutter: Electromyographic Evidence during Speech and Non-Speech
}

\author{
Ai Leen Choo ${ }^{a, b} \quad$ Michael P. Robb ${ }^{b, d} \quad$ John C. Dalrymple-Alford ${ }^{c-e}$ \\ Maggie-Lee Huckabee ${ }^{b, d}$ Greg A. O'Beirne ${ }^{b, d}$ \\ a University of Illinois, Urbana, III., USA; Departments of ${ }^{\mathrm{b}}$ Communication Disorders and ${ }^{\mathrm{C}}$ Psychology, \\ University of Canterbury, ${ }^{d}$ Van der Veer Institute for Parkinson's and Brain Research, and eDepartment of \\ Medicine, University of Otago, Christchurch, New Zealand
}

\section{Key Words}

Asymmetry · Cerebral laterality · Electromyography • Lips • Speech · Stuttering

\begin{abstract}
The present study examined whether abnormal cerebral control was evident in the lip movements of adult stutterers (AS) compared to non-stutterers (ANS), as demonstrated during speech and non-speech tasks. Electromyographic (EMG) activity during production of words with initial/f/and $/ \mathrm{p} /$ phonemes, single-sentence production and lip pursing were measured. Differences between AS and ANS were evident in all tasks. For AS, the highest EMG amplitude was in the region of the left lower lip, which is indicative of greater right hemisphere participation. However, in ANS the right lower lip displayed the highest EMG amplitude, suggesting greater left hemisphere participation. Further, AS showed greater asynchronous lip activity than ANS for all tasks. These results support the hypotheses of reversed lateralization for speech and non-speech processing and reduced coordination of speech musculature in AS.
\end{abstract}

Copyright $\odot 2010$ S. Karger AG, Basel
(C) 2010 S. Karger AG, Basel

1021-7762/10/0623-0143\$26.00/0

Fax +4161306 1234

E-Mail karger@karger.ch

www.karger.com
Accessible online at: www.karger.com/fpl

\section{Introduction}

\section{Cerebral Anomalies Related to Stuttering}

The Orton-Travis theory developed in the late 1920s suggested that stuttering was a consequence of aberrant cerebral laterality in the processing and production of speech [1]. However, it was not until the advent of neuroimaging techniques that these speculations could be substantiated. Adults stutterers (AS) have demonstrated anomalous cerebral volume, composition and gyrification, which typically favor the right hemisphere $[2,3]$.

Modern imaging techniques have further documented anomalous patterns of cerebral activation in AS during fluent and disfluent speech production. For example, Fox et al. [4] reported overactivation of the motor system during moments of stuttering with prominent right hemisphere lateralization of the primary and extraprimary cortices. Braun et al. [5] found that during fluent speech, the left inferior frontal and primary auditory cortices (i.e. areas associated with self-monitoring, comprehension and fluency) were activated in non-stutterers (ANS) but not in AS. Following a period of stuttering treatment, AS were reported to increase activation of the left hemisphere [6, 7]. 


\section{Stuttering and Electromyography}

Stuttering is often regarded as a corollary of aberrant speech muscle coordination. Electromyography (EMG) studies in stuttering have documented atypical levels of activity and discoordination of the lip musculature in AS. Code [8] compared moments of stuttering in AS to pseudo-stuttering produced by ANS and found larger amplitudes and longer durations of EMG activity during a moment of stuttering than during a pseudo-stutter produced by ANS. Studies have documented discoordination and mis-sequencing of the lip muscles in AS [9]. In addition, AS demonstrate more variability in the duration between voice onset and onset of lower lip movement [10].

\section{EMG and Laterality}

One of the most intriguing issues to arise from EMG studies of the general population is the notion of laterality and facial expressions. Mouth asymmetry is directly correlated with the degree of hemisphere participation [11]. The upper facial muscles are bilaterally innervated, while the lower facial muscles are contralaterally innervated, with the largest group associated with the mouth. Laterality of facial expression during speech production is an observable phenomenon, even to the untrained eye, and can be substantiated by EMG. Graves and Potter [12] found a tendency for people (i.e. ANS) to show elevated EMG levels on the right side of the mouth, indicative of left cerebral lateralization for speech.

\section{Present Study}

Past stuttering research has revealed differences in cerebral anatomy and neural activation between AS and ANS $[3,13]$. These studies indicate that stuttering is associated with anomalous cerebral activity that favors the right hemisphere. Presumably, these laterality differences between AS and ANS are not confined to the brain. Rather, these differences may also be apparent in the neuromuscular pathways subserving speech formulation and production. The present study was designed to examine whether abnormal cerebral control was evident in the lip movements of AS compared to ANS. Assuming ANS show a general tendency towards elevated EMG levels on the right side of the mouth, indicative of left cerebral lateralization for speech, we hypothesized that AS would show an opposite pattern of EMG activation. That is, AS would show elevated levels on the left side of the mouth, indicative of right cerebral lateralization for speech.

\section{Method}

\section{Participants}

Ten adult males (5 AS, mean age 26 years; 5 ANS, mean age 25 years) participated in the study. The AS participants ranged in stuttering severity from very mild to moderate [14]. All participants were right-handed [15], ranging from 88 to $100 \%$. They were free of neurological and health problems based on personal report.

\section{Equipment and Electrode Placement}

The EMG signals were recorded with miniature $\mathrm{Au} / \mathrm{AuCl}$ disk electrodes placed around the perimeter of the mouth to identify muscle activity associated with the orbicularis oris inferior and orbicularis oris superior muscles. Surface electrodes were placed in pairs in 4 quadrants: (1) left upper lip, (2) right upper lip, (3) left lower lip, and (4) right lower lip. Each pair of bipolar electrodes was placed approximately $1 \mathrm{~cm}$ apart, centered within each quadrant, and positioned as close as possible to the vermilion border of the lips parallel to the muscle fiber direction. Electrodes were referenced against the forehead at midline with a ground electrode placed on the right earlobe.

\section{Speech and Non-Speech Samples}

Lip muscle activity was examined in 2 fluent single-word production tasks, one oral reading task and one lip pursing task. For each single-word production task, participants named aloud 4 pictures containing either a word-initial /f/ or /p/ phoneme (i.e. fish, four, pig and purse). Each word was produced 5 times for a total of 20 single-word productions (10/f/ productions and $10 / \mathrm{p} /$ productions). The oral reading task involved production of the first line of the 'Grandfather Passage' [16], 'you wished to know all about my grandfather'. All sentences were read at a normal reading rate and produced 5 times. For the non-speech task, participants were asked to purse their lips as they would when saying the word 'pool'. This task was completed 20 times for each participant.

\section{Data Collection Procedures}

Prior to collection of the speech and non-speech samples, participants were seated in a relaxed position approximately one-half meter from a laptop computer. Instructions were given verbally and also presented on the computer screen. Following an approximately 3-second period of time, 1 of 4 options would appear on the screen: (1) a /p/ picture, (2) an /f/ picture, (3) the 'Grandfather Passage', or (4) a 'lip pursing' symbol. At the completion of each task, participants were instructed to relax their lips and facial muscles. All tasks were presented in randomized order.

\section{Signal Analysis}

Lip activity was recorded on EMG bipolar channels with a low pass of $200 \mathrm{~Hz}$ and a high pass of $1 \mathrm{~Hz}$ with an AD rate of 1,000. For each participant, the average peak EMG amplitude was determined for each task using specially designed software. Reliability for the measurement of peak EMG amplitude was performed on $100 \%$ of the data set. Re-measurement accuracy was $100 \%$. 
Table 1. Peak EMG values for AS $(\mu \mathrm{V})$

\begin{tabular}{|c|c|c|c|c|c|c|c|c|c|c|c|c|c|c|c|c|}
\hline & \multicolumn{4}{|c|}{ f-Words } & \multicolumn{4}{|c|}{ p-Words } & \multicolumn{4}{|c|}{ Sentences } & \multicolumn{4}{|c|}{ Lip pursing } \\
\hline 1 & 6.7 & 43.2 & 11.2 & 8.2 & 8.1 & 38.8 & 12.7 & 13.5 & 16.8 & 74.8 & 19.4 & 9.8 & 26.6 & 95.0 & 19.9 & 13.5 \\
\hline 2 & 29.3 & 4.4 & 27.8 & 18.5 & 14.9 & 5.3 & 37.4 & 14.0 & 25.6 & 7.0 & 34.8 & 24.6 & 13.8 & 3.9 & 32.0 & 14.4 \\
\hline 3 & 83.5 & 28.0 & 297.6 & 17.1 & 90.3 & 51.5 & 182.0 & 15.0 & 137.7 & 146.5 & 500.4 & 28.7 & 323.4 & 56.1 & 847.1 & 61.6 \\
\hline Mean & 29.1 & 23.0 & 79.3 & 11.2 & 30.2 & 43.4 & 58.2 & 11.5 & 45.9 & 68.8 & 122.7 & 16.2 & 85.6 & 53.7 & 202.5 & 23.7 \\
\hline SD & 28.2 & 14.3 & 109.5 & 5.5 & 30.2 & 37.3 & 62.7 & 3.6 & 46.0 & 53.0 & 188.9 & 8.7 & 19.0 & 37.3 & 322.8 & 19.0 \\
\hline
\end{tabular}

Table 2. Peak EMG values for ANS $(\mu \mathrm{V})$

\begin{tabular}{|c|c|c|c|c|c|c|c|c|c|c|c|c|c|c|c|c|}
\hline & \multicolumn{4}{|c|}{ f-Words } & \multicolumn{4}{|c|}{ p-Words } & \multicolumn{4}{|c|}{ Sentences } & \multicolumn{4}{|c|}{ Lip pursing } \\
\hline & $\begin{array}{l}\text { left } \\
\text { upper }\end{array}$ & $\begin{array}{l}\text { right } \\
\text { upper }\end{array}$ & $\begin{array}{l}\text { left } \\
\text { lower }\end{array}$ & $\begin{array}{l}\text { right } \\
\text { lower }\end{array}$ & $\begin{array}{l}\text { left } \\
\text { upper }\end{array}$ & $\begin{array}{l}\text { right } \\
\text { upper }\end{array}$ & $\begin{array}{l}\text { left } \\
\text { lower }\end{array}$ & $\begin{array}{l}\text { right } \\
\text { lower }\end{array}$ & $\begin{array}{l}\text { left } \\
\text { upper }\end{array}$ & $\begin{array}{l}\text { right } \\
\text { upper }\end{array}$ & $\begin{array}{l}\text { left } \\
\text { lower }\end{array}$ & $\begin{array}{l}\text { right } \\
\text { lower }\end{array}$ & $\begin{array}{l}\text { left } \\
\text { upper }\end{array}$ & $\begin{array}{l}\text { right } \\
\text { upper }\end{array}$ & $\begin{array}{l}\text { left } \\
\text { lower }\end{array}$ & $\begin{array}{l}\text { right } \\
\text { lower }\end{array}$ \\
\hline 1 & 4.8 & 5.6 & 6.6 & 21.7 & 5.5 & 6.0 & 13.7 & 26.2 & 8.4 & 7.9 & 13.5 & 40.1 & 5.8 & 8.9 & 9.8 & 30.8 \\
\hline 2 & 209.5 & 294.6 & 82.3 & 484.8 & 175.9 & 134.6 & 64.5 & 236.6 & 304.9 & 302.5 & 264.2 & 663.2 & 132.5 & 143.9 & 77.2 & 674.3 \\
\hline 3 & 6.3 & 4.6 & 13.1 & 101.6 & 5.8 & 4.8 & 9.4 & 42.9 & 6.6 & 6.4 & 18.3 & 73.4 & 11.3 & 9.2 & 9.7 & 55.2 \\
\hline Mean & 47.6 & 63.1 & 23.1 & 131.2 & 42.6 & 34.5 & 21.8 & 71.4 & 69.8 & 84.9 & 63.6 & 166.9 & 38.1 & 40.5 & 21.9 & 173.3 \\
\hline SD & 80.9 & 115.7 & 29.7 & 179.7 & 66.7 & 50.2 & 83.3 & 21.3 & 117.6 & 114.7 & 100.3 & 249.0 & 47.7 & 52.6 & 27.7 & 252.4 \\
\hline
\end{tabular}

\section{Results}

The individual and mean EMG values obtained for each lip location for the speech and non-speech tasks are presented in table 1 for the AS participants and table 2 for the ANS participants. The main aim was to investigate left side versus right side, and there was a clear expectation that the lower lip would be more informative concerning laterality differences than upper lip. For each task, we calculated a within-subject 'difference score' for the EMG measure obtained from the left and right lower lip and evaluated the 2 groups using a Mann-Whitney U statistic. We then made the same analysis for the left and right upper lip. Finally, a Pearson correlation was calculated between all pairs of lips sites for each participant group to determine whether the pattern of EMG activity was similar across the 2 groups.

All 3 speech tasks $(p<0.001)$ and the lip-pursing nonspeech task $(p<0.001)$ revealed a significant difference between the AS and ANS groups in terms of the withinsubject EMG difference score for left lower lip quadrant versus the right lower lip quadrant. As shown in figure 1, the AS group showed a greater left-sided (right hemisphere) EMG bias for the lower lip in each condition. By contrast, the ANS group showed the expected right-sided (left hemisphere) bias for the lower lip in each condition. No significant between-group differences were found in EMG laterality measures for the upper lips.

Among the AS group, only 1 correlation (left upper/ left lower, min. $r=0.97$, max. $r=0.99 ; p<0.001$ ) was significant for any speaking task, indicating that when the peak amplitude of left-upper was high, so too was the amplitude of the left-lower site. Analyses among EMG measures for the AS group for the non-speech task revealed 3 comparisons that were correlated (i.e. left upper/left lower, left upper/right lower and left lower/right lower; $r=$ $0.99 ; \mathrm{p}<0.001$ ), indicating that when the peak amplitude of one location was high, so too was the amplitude of oth- 


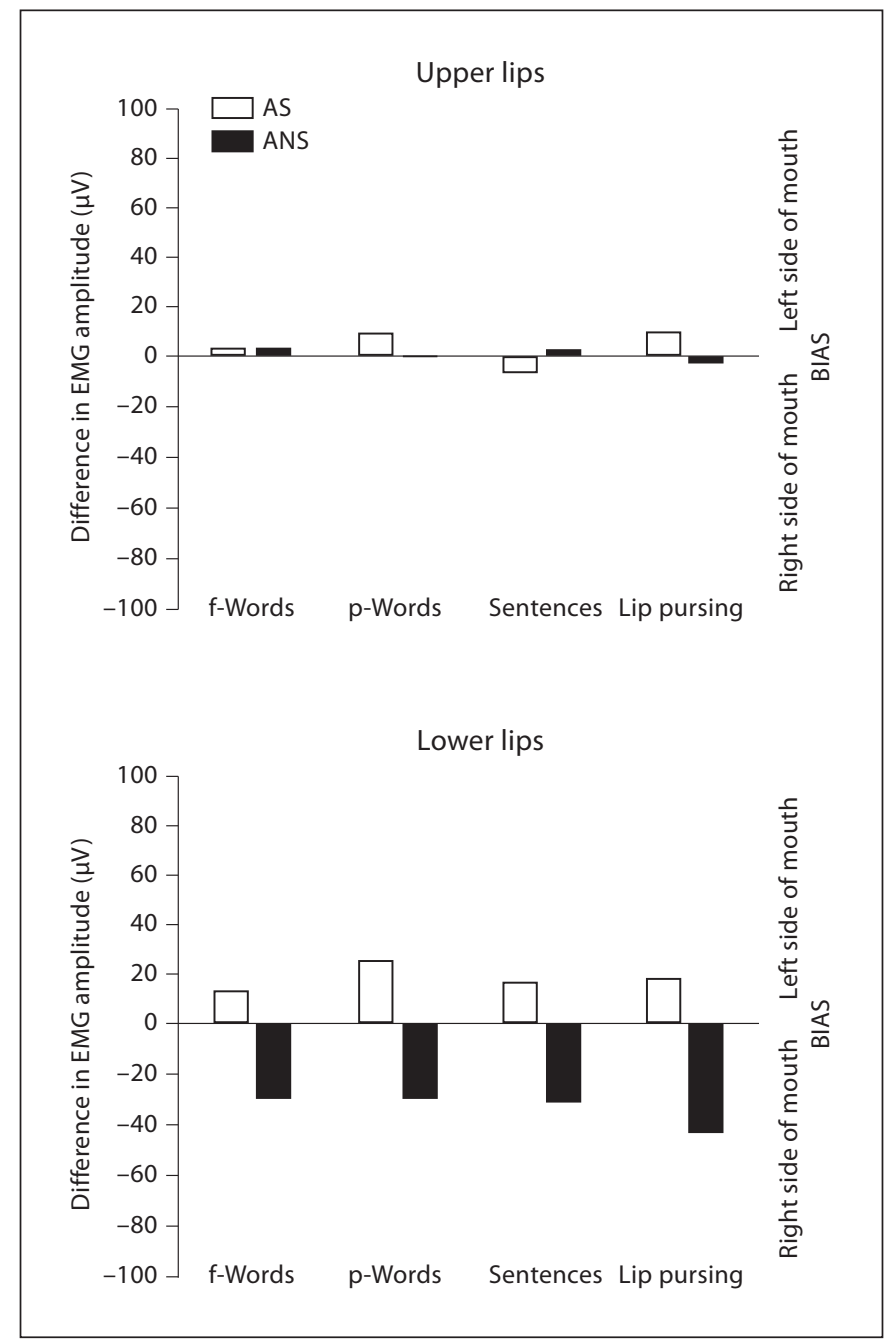

Fig. 1. Group (peak) EMG difference score between the left and right upper and lower lips. Values are medians.

er sites. For the ANS group, all possible lip comparisons were correlated for the speaking and non-speech tasks (min. $\mathrm{r}=0.94$, max. $\mathrm{r}=0.98 ; \mathrm{p}<0.001$ ).

\section{Discussion}

\section{Cerebral Participation and Lip Asymmetry}

Despite the small sample size, the pattern of EMG signal observed in the present study provides clear support for the hypothesis of anomalous cerebral laterality in AS. The study also shows the value of EMG as an indication of cerebral participation at the moment of speech production. There were significant differences between the AS and ANS groups in regard to the peak EMG amplitude between the left and right sides of the lower lip for both speech and non-speech tasks. For both groups, the highest peak EMG activity was found in the lower (but opposite) regions of the mouth. The lowest EMG amplitude was also in direct opposition for AS and ANS. This pattern of lip activity for AS and ANS is in concordance with previous investigations and assumed to be a corollary of differences in cerebral laterality between the 2 groups [12, 17].

The results of the correlation analysis were also suggestive of distinct patterns of EMG activation for each group. Among the ANS group, all combinations of lip pairings of the 4 mouth locations were correlated with one another for both speech and non-speech tasks demonstrating highly coordinated lip muscle activity across all tasks. Interestingly, a similar relationship was not found for the AS group with the exception of the LU-LL sites, which showed correlated EMG activity during speech and non-speech tasks. The poorer correlation for the remaining lip muscle groupings for the AS compared to ANS may indicate reduced performance as a consequence of right cerebral contribution since the right hemisphere is better suited for non-linguistic processing [6].

\section{Other Basis for Lip Asymmetry}

Wolf and Goodale [18] posit that lip asymmetry is a consequence of the efficiency of the right lip in initiating movement as a result of direct neural access. The contralateral pathway is functionally stronger than the ipsilateral pathway. The right lip is also anticipated to open slightly larger than the left lip at any given time since it initiates movement sooner than the left lip [19]. In addition, functional muscle asymmetry of the lips may result from asymmetry of muscle strength or development. For example, asymmetry of gait is associated with asymmetry of muscle strength [20]. In most right-handed individuals, the right side of the body is stronger and the right limb initiates movement, while the left limb is responsible for support [21]. Accordingly, lip asymmetry may be associated with asymmetry of facial muscle strength.

Graves and Landis [11] found that right-handed males in the general population showed higher instances of right lip asymmetry than left-handed males. This suggests that lip asymmetry may feature a similar trend to limb asymmetry. The right lip may initiate movement due to greater muscle strength. In light of the present findings, the opposite pattern of lip asymmetry found for AS may indicate greater strength on the left side of the 
face and earlier initiation of mouth movement with the left lip. Furthermore, initiation of lip movement may be coupled with the timing of cerebral activation. In several investigations of verbal and non-verbal oral movement in ANS, activation of the left cerebral hemisphere preceded the right $[22,23]$. Hence, earlier initiation of right mouth movement may be a consequence of earlier activation of the left cerebral hemisphere. Therefore, the reversed pattern of lip asymmetry in AS may reflect reduced connection between the right lip and left cerebral hemisphere, reduced right facial muscle strength, and/or activation of the right cerebral hemisphere prior to the left.

\section{Conclusion}

The finding of the present study supports previous investigations documenting right lip asymmetry in ANS $[11,12]$, which is generally assumed to be a corollary of the left cerebral specialization for speech execution [19]. In contrast, a left lip bias was found for AS and would appear to suggest that speech motor execution involves right hemisphere activation in this group of speakers.

\section{References}

1 Orton ST: Studies in stuttering. Arch Neural Psychiatry 1928;18:671-672.

2 Foundas AL, Corey DM, Angeles V, Bollich AM, Crabtree-Hartman E, Heilman KM: Atypical cerebral laterality in adults with persistent developmental stuttering. Neurol 2003;61:1378-1385.

-3 Jancke L, Hanggi J, Steinmetz H: Morphological brain differences between adult stutterers and non-stutterers. BMC Neurol 2004; 4:23-28.

-4 Fox PT, Ingham RJ, Ingham JC, Hirsch TB, Hunter Downs J, Martin C, Jerabek P, Glass T, Lancaster JL: A PET study of the neural systems of stuttering. Nature 1996;382:158162.

5 Braun AR, Varga M, Stager S, Schulz G, Selbie S, Maisog JM, Carson RE, Ludlow CL: Altered patterns of cerebral activity during speech and language in developmental stuttering. An $\mathrm{H}_{2}{ }^{15} \mathrm{O}$ positron emission tomography study. Brain 1997;120:761-784.

6 6 De Nil L, Kroll RM, Lafaille SJ, Houle S: A positron emission study of the short- and long-term effects on functional brain activation in adults who stutter. J Fluency Dis 2003; 28:357-380.

7 Giraud A, Neumann K, Bachoud-Levi A, von Gudenberg AW, Euler HA, Lanfermann H, Preisbich C: Severity of dysfluency correlates with basal ganglia activity in persistent developmental stuttering. Brain Lang 2008; 104:190-199.
8 Code C: Genuine and artificial stammering: an EMG comparison. Br J Comm Dis 1979; 14:5-16.

-9 Hulstijn W, Summers JJ, van Lieshout PHM, Peters HFM: Timing in finger tapping and speech: a comparison between stutterers and fluent speakers. Hum Mov Sci 1992;11:113124.

10 van Lieshout PHHM, Hulstijn W, Peters HFM: Speech production in people who stutter: testing the motor plan assembly hypothesis. J Speech Hear Res 1996;39:76-92.

11 Graves R, Landis T: Asymmetry in mouth opening during different speech tasks. Int J Psychol 1990;25:179-189.

12 Graves R, Potter S: Speaking from two sides of the mouth. Visible Lang 1988;22:128-137.

13 De Nil L, Kroll RM, Kapur S, Houle S: A positron emission tomography study of silent and oral single word reading in stuttering and nonstuttering adults. J Speech Lang Hear Res 2000;43:1038-1053.

14 Riley G: Stuttering Severity Instrument for Children and Adults, ed 3. Austin, Pro-Ed, 1994.

15 Oldfield RC: The assessment and analysis of handedness: the Edinburgh Inventory. Neuropsychologia 1971;9:97-113.

16 Darley FL, Aronson AE, Brown JR: Motor Speech Disorders. Philadelphia, Saunders, 1975.
17 Code C, Lincoln M, Dredge R: Asymmetries in mouth opening during word generation in male stuttering and non-stuttering participants. Laterality 2005;10:471-486.

18 Wolf ME, Goodale MA: Oral asymmetries during verbal and non-verbal movements of the mouth. Neuropsychologia 1987;25:375396.

19 Nicholls MER, Searle DA: Asymmetries for the visual expression and perception of speech. Brain Lang 2006;97:322-331.

20 Maupas E, Paysant J, Daite AM, Martinet N, André JM: Functional symmetries of the lower limbs: a comparison between clinical assessment of laterality, isokinetic evaluation and electrogoniometric monitoring of knees during walking. Gait Posture 2002;16: 304-312.

21 Sadeghi H, Allard P, Prince F, Labelle H: Symmetry and limb dominance in able-bodied gait: a review. Gait Posture 2000;12:3445.

22 Palolahti M, Leino S, Jokela M, Kopra K, Paavilainen P: Event-related potentials suggest early interaction between syntax and semantics during on-line sentence comprehension. Neurosci Lett 2005;384:222-227.

23 Saarinen T, Laaksonen H, Parviainen T, Salmelin R: Motor cortex dynamics in visuomotor production of speech and non-speech mouth movements. Cereb Cortex 2006;16: 212-222. 